\title{
Construção de um conceito de cuidado de enfermagem: contribuição para o ensino de graduação*
}

\author{
Construction of a nursing care concept: contribution for undergraduate nursing education
}

Conctrucción de un concepto de atención de enfermería: contribución para la enseñanza del grado en enfermería

\author{
Eucléia Gomes Vale', Lorita Marlena Freitag Pagliuca' \\ 'Universidade Federal do Ceará. Departamento de Enfermagem. Fortaleza, CE
}

Submissão: $27 / 10 / 2009$

Aprovação: 26/09/2010

\section{RESUMO}

Objetivou-se construir um conceito de cuidado de enfermagem, a partir da compreensão de enfermeiros e alunos de um curso de graduação. Tratou-se de pesQuisa Qualitativa, Que utilizou o grupo focal para construção de um conceito de cuidado de enfermagem a ser utilizado no ensino de graduação. Realizada na Faculdade Católica Rainha do Sertão em Quixadá, CE, Brasil, no período de agosto a dezembro de 2007. Três categorias emergiram do processo: a compreensão do conceito de cuidado, o cuidado de enfermagem e o significado do cuidado. $\mathrm{O}$ conceito construído envolveu atitudes de consciência, ética, zelo, solidariedade e amor que expressam um "saber-fazer" embasado na ciência, na arte, na ética e na estética, direcionado às necessidades do indivíduo, da família e da comunidade.

Descritores: Formação de conceito; Educação em enfermagem; Cuidados de enfermagem; Enfermagem.

\section{ABSTRACT}

The purpose of this research was to construct a nursing care concept, based on the understanding of nurses and students from an undergraduate course. This is a Qualitative study. A focus group was used to construct a nursing care concept for use in undergraduate teaching. The research was carried out at Faculdade Católica Rainha do Sertão in Quixadá, CE, Brazil, from August to December 2007. Three categories emerged from the process: the understanding of the care concept, nursing care and the meaning of care. The constructed concept involved attitudes of awareness, ethics, zeal, solidarity and love, which express a "know-how" based on science, art, ethics and esthetics, directed at individual, family and community needs.

Key words: Concept formation; Education, nursing; Nursing Care; Nursing.

\section{RESUMEN}

El objetivo del estudio hay sido construir un concepto de atención de enfermería, desde la comprensión de enfermeros y estudiantes del grado en enfermería. Se trata de una investigación cualitativa, Que ha utilizado el grupo focal para la construcción de un concepto de atención de enfermería para utilización en la enseñanza de graduación. Realizada en la Faculdade Católica Rainha do Sertão en Quixadá, CE, Brasil, en el período de agosto a diciembre de 2007. Tres categorías emergieron del proceso: la comprensión del concepto de cuidado, la atención de enfermeríay el significado del cuidado. El concepto construido implicaron actitudes de la conciencia, ética, dedicación, solidaridad y amor que expresan un "saber-hacer" basado en la ciencia, en la arte, en la ética y en la estética, direccionado a las necesidades individuales, de los familiares y de la comunidad.

Descriptores: Formación de concepto; Educación en enfermería; Atención de enfermería; Enfermería. 


\section{INTRODUÇÃO}

O processo de cuidar e a formação acadêmica do profissional enfermeiro tem sido ao longo dos anos, nosso objeto de reflexão e estudo. Na busca constante para contribuir com a formação de enfermeiros aptos a intervirem no processo saúde-doença por meio da utilização de cuidados competentes, humanizados, éticos e eficazes, temos procurado colaborar na implementação de mudanças, na forma de pensar-fazer-ensinar enfermagem. Apesar de todo o esforço empreendido por enfermeiros docentes e assistenciais interessados em melhorar o ensino de enfermagem e, consequentemente, a prática dos enfermeiros, conforme percebemos, ainda é comum encontrar recém-formados Que se sentem despreparados e imaturos para exercerem a profissão.

A nosso ver o foco da atenção da enfermagem é o ser humano, com suas necessidades bio-psico-sócio-espirituais e a função precípua do enfermeiro é o cuidado de enfermagem, cujo objetivo centra-se na promoção da saúde, na prevenção de doenças e na recuperação e reabilitação da saúde. Como toda ciência, a enfermagem carece consolidar um corpo de conhecimentos próprios e uma linguagem específica Que permitam aos seus exercentes compreender seu fazer e, assim, prestar cuidados significativos capazes de atender às reais necessidades dos seres humanos por eles assistidos.

No seu dia-a-dia, os profissionais de enfermagem utilizam a ciência, a arte, a estética e a ética no processo de promoção, manutenção e recuperação da saúde, por meio de ações de cuidado destinadas a ajudar as pessoas a viverem mais saudáveis e, Quando preciso, a superarem os efeitos da doença como um fenômeno social, existencial, cultural e transitório. O cuidado pensado autenticamente como existencial, essencial do ser humano, diz respeito a zelo, desvelo, atenção, bom trato e solicitude, constituindo-se, dessa forma, um fundante por meio do Qual a pessoa sai de si para se centrar na preocupação com o outro. Para o autor, o cuidado é o caráter existencial mais próprio do ser humano ${ }^{(1)}$.

A partir do final da década de 1970, com maior ênfase na última década do século passado, o cuidado vem sendo discutido e tornouse foco de muitas pesquisas realizadas por enfermeiros. Na década de 1990 passou a ser o marco referencial em um momento de mudanças significativas na enfermagem, com vistas a uma nova forma de pensar-fazer-ensinar-aprender enfermagem.

O cuidado é indispensável ao ser humano, o cuidado como essência da Enfermagem e como função precípua do enfermeiro há de ser conceituado e compreendido por todos, com a perspectiva de dar sentido ao fazer da enfermagem para os Que oferecem cuidados (enfermeiras assistenciais), para Quem recebe os cuidados (pacientes/ clientes), para educadores e educandos da área de Enfermagem.

Entre as necessidades de desenvolvimento de conceitos de Enfermagem, o processo de fazer-ensinar enfermagem requer a compreensão do conceito de cuidado e do processo de cuidar em enfermagem. Desse modo, o fazer e o ensinar poderão ter significado para todos os envolvidos neste processo - enfermeiros e alunos de enfermagem - e, ainda, possibilitarão a construção de outros conceitos Que atendam ao processo fazer-ensinar enfermagem nos diversos cenários da prática de enfermagem.

Ressaltamos Que na literatura, a enfermagem busca desenvolver e clarificar o conhecimento e para tanto tem voltado seus estudos para a compreensão de conceitos e para a resolução de problemas conceituais ${ }^{(2)}$. A atitude investigativa é indispensável para o exercício de uma prática científica e sistematizada, Que se consolida por meio da avaliação clínica e na utilização e aplicação das evidências externas à realidade observada ${ }^{(3)}$.

O cuidado como função precípua da enfermagem, apesar dos vários estudos realizados e das discussões empreendidas, parece não ter sido compreendido em sua essência.

Assim, para ocorrer esta compreensão, urge a análise e construção do conceito de cuidado de enfermagem com vistas ao ensino de graduação, no momento em Que a enfermagem brasileira tenta implementar e avaliar as mudanças ora referidas. Neste contexto o cuidado, ao ser compreendido, poderá ser vivenciado e ensinado, e, assim, trará o homem com suas necessidades para o centro do pensar e do agir, no ensinar e fazer Enfermagem.

No processo de saber-fazer-ensinar enfermagem, com ênfase no cuidado nos cenários da prática hospitalar, na saúde pública e na academia, nossa grande preocupação sempre esteve e, ainda permanece, no ato de cuidar e na forma como este é ensinado nos cursos de graduação em enfermagem. Diante do exposto este estudo possui o seguinte objetivo: construir um conceito de cuidado de Enfermagem, a partir da compreensão de enfermeiros docentes e assistenciais e de alunos de um curso de graduação em enfermagem.

\section{MÉTODOS}

Neste estudo optou-se pela pesquisa Qualitativa como método de estudo por se entender que este se adéqua ao objetivo pretendido. Assim, apresentamos uma explanação sobre a pesQuisa Qualitativa como método e o grupo focal como estratégia de coleta de dados. Finalmente, descrevemos o planejamento da pesquisa e os aspectos éticos observados.

O método Qualitativo caracteriza-se como aquele Que Quer entender como o objeto de estudo ocorre ou se manifesta. Conforme destaca, este não almeja o produto, ou seja, o resultado final matematicamente trabalhado ${ }^{(4)}$. Na peseuisa Qualitativa buscamos o significado da ação humana, Que constrói a história por meio de um grupo de técnicas Que possibilitam a elaboração da realidade, onde a teoria e a metodologia caminham juntas, compondo um conjunto de procedimentos direcionados para a revelação do fenômeno em estudo $^{(5)}$.

O Curso de Enfermagem da Faculdade Católica Rainha do Sertão (FCRS) está situado no município de Quixadá, CE, geograficamente localizado na região do sertão central. Foi instalado em abril de 2004 e seu Projeto Político Pedagógico (PPP) tem por finalidade adequar o processo de formação do enfermeiro às transformações das profissões da área da saúde, do ensino e, principalmente, às necessidades e demandas de saúde da população, expressas pela significante mudança no seu perfil demográfico-epidemiológico.

\section{Grupo focal como estratégia de coleta de dados}

Neste estudo utilizamos o grupo focal no modo multimétodos ${ }^{(6)}$, pois, este possibilita o surgimento de novas idéias pela busca nas bases de dados e pela participação dos sujeitos da pes@uisa mediante suas experiências e opiniões, obtidas por meio da interação. Nesta interação, um membro do grupo responde a outro, expressando acordo ou desacordo, mediante Questionamentos, recebendo e fornecendo respostas. Ocorrem, também, a divisão e a comparação de idéias e 
experiências, e, nesse momento, temos a oportunidade de apreender como os participantes compreendem as similaridades e diferenças e a partir daí retirar as evidências.

A composição do grupo foi intencional. Escolhemos Quatro enfermeiras docentes Que lecionam disciplinas que enfocam cuidados, seis alunos do $8^{\circ}$ semestre do Curso de Graduação de Enfermagem da FCRS (por estarem em fase de conclusão de curso) e Quatro enfermeiras das instituições de saúde onde os alunos exercem suas práticas. Além da nossa participação como moderadora do grupo, participaram ainda uma psicóloga e dois estudantes de enfermagem do $8^{\circ}$ semestre, Que atuaram como membros observadores das sessões grupais. Para a escolha dos participantes, o único critério foi ter o cuidado de enfermagem como foco na sua prática de ensinar, fazer ou aprender.

As reuniões ocorreram no período de agosto a dezembro de 2007. O número de encontros esteve diretamente atrelado ao alcance dos objetivos propostos no estudo. Ocorreram nove sessões com os objetivos: 1) estabelecer o contrato grupal, estimular o entrosamento e iniciar o debate; 2) discutir os conceitos de cuidado de enfermagem; 3) discutir o uso do conceito de cuidado de enfermagem, com propósito de identificar seus atributos; 4) dar continuidade às discussões sobre atributos do cuidado; 5) apresentar os atributos consensuados e os atributos essenciais; identificar antecedentes e conseQuentes do cuidado de enfermagem; 6) apresentar atributos essenciais, antecedentes e consequentes do cuidado de enfermagem; identificar o que dá significado ao cuidado; explicitar os aspectos que especificam a ocorrência do cuidado de enfermagem; 7) discutir definições sobre "conceito" para embasar a formulação do conceito de cuidado de Enfermagem; 8) resgatar as discussões sobre conceitos; construir coletivamente o conceito de cuidado de enfermagem; 9) validar o conceito de cuidado de enfermagem construído pelo grupo; conhecer a opinião dos elementos do grupo focal sobre sua participação na elaboração de um conceito de cuidado de enfermagem para o ensino de graduação.

Os encontros foram gravados em áudio e seu conteúdo transcrito e analisado. Como preparação para cada sessão, o material anterior era sintetizado e apresentado ao grupo acompanhado de guias de temas no intuito de facilitar a participação e favorecer o alcance dos objetivos propostos em cada sessão. Os guias de temas foram elaborados com base nos autores Que abordam o tema "cuidado no ensino de enfermagem" em literatura nacional e internacional, bem como nos resultados de cada sessão do grupo focal.

De acordo com os preceitos éticos, devemos preservar o anonimato dos participantes. Assim, para manter em sigilo as identidades dos participantes do grupo focal, estes foram identificados em seus depoimentos por meio de siglas e números. Enquanto as siglas correspondem às palavras Grupo Focal (GF) e Participante (P), os números correspondem ao número da sessão do grupo focal, variável de um a nove, e o número Que designa cada participante, variável de um a Quatorze. Como exemplo, a fala GF2PI I significa Que a fala foi emitida no grupo focal dois pelo participante 11 .

Este estudo cumpriu o recomendado na Resolução no 196 de 10 de outubro de 1996, do Conselho Nacional de Saúde ${ }^{(7)}$, foi submetido à avaliação do Comitê de Ética em PesQuisa da Universidade Federal do Ceará (COMEPE) e receber parecer favorável (Parecer n 164/07). Os sujeitos do estudo assinaram Termo de Consentimento Livre e Esclarecido, e mantido o anonimato conforme descrito acima.

\section{RESULTADOS E DISCUSSÃO}

\section{Processo de construção do conceito de cuidado de enfermagem}

As sessões do grupo focal foram desenvolvidas obedecendo a etapas preconizadas no Modelo de Análise de Conceito Evolucionário, a saber: identificação do conceito de interesse (Cuidado de Enfermagem); identificação e seleção do campo apropriado para a coleta de dados (Curso de Graduação em Enfermagem da FCRS); coleta de dados (com os sujeitos do estudo) reconhecendo os atributos do conceito e identificação suas características; identificação de antecedentes e consequentes do conceito; e a construção do conceito ${ }^{(2)}$.

Nestas seções, os elementos fluíram por meio das unidades de significados componentes das três categorias oriundas das falas dos participantes do grupo focal, Que possuem relação com as etapas do modelo ora referido, Que foram denominadas: (Categorial) A compreensão do conceito de cuidado - a interação entre o discurso e a prática; (Categoria 2) O cuidado de enfermagem - antecedentes e consequentes; e (Categoria 3) O significado do cuidado - o concreto e o subjetivo na relação entre seres humanos. As categorias são apresentadas a seguir.

\section{Categoria 1}

\section{A compreensão do conceito de cuidado - a interação entre o discurso e a prática}

Esta categoria apresenta aspectos do cuidado de enfermagem Que possuem relação com a determinação dos atributos e Que buscam as características do conceito. Foram identificados como atributos gerais: interação, amor, solidariedade, responsabilidade, consciência, zelo, compaixão, ensino, ética e interesse. Após debate, o grupo selecionou como atributos essenciais: amor; zelo; consciência; solidariedade; e ética.

O amor, como atributo essencial do cuidado, permeou a construção do conceito de cuidado de enfermagem, objeto deste estudo, e foi sempre abordado em todas as falas, ora de forma objetiva e explícita, e em outros momentos de maneira subjetiva.

Este sentimento é percebido de forma clara nas falas de alguns componentes do grupo focal.

Eu vejo o cuidado como expressão do amor, se preocupar com o bem-estar do outro, com a felicidade do outro e você ir ao encontro de tal forma que você se coloca no lugar do outro, identifica as suas necessidades, sabe separar o que é vontade do que é necessidade. (GFIP2)

Cuidado envolve amor porQue é uma relação de interiorizar o outro, fazer-me presente numa realidade Que não é a minha. Não é apenas agir tecnicamente, é ter preocupação com o bem-estar do outro. (GFIP7)

Quanto à palavra zelo, selecionada pelos participantes como atributo essencial do cuidado de Enfermagem, tem como significado, "afeição ou dedicação, cuidado, desvelo ardente por alguém ou por algo" ${ }^{(8)}$, sentido similar ao atributo amor. No próprio significado da 
palavra zelo, está a palavra cuidado. Portanto, o zelo é inerente ao cuidado. Não é possível existir cuidado sem zelo, como mostram as falas dos participantes:

O cuidado envolve obrigatoriamente o zelo. Se há cuidado, há zelo e desvelo pelo ser cuidado. (GFIPI3)

\section{Se não há zelo, não há relação e conseQüentemente não há cuidado.} (GFIP3)

Na categoria "cuidar como afeto", a intensidade dos sentimentos de emoção, compaixão ou empatia influi no emocional da enfermeira, e, desse modo, influenciará no ato de cuidar, pois os profissionais de enfermagem trabalham no limiar entre a vida e a morte ${ }^{(9)}$.

Ao selecionarem a consciência como atributo do cuidado de Enfermagem, os participantes do grupo focal assim se expressaram:

Ao tomar consciência do que é cuidado, a enfermeira usa os conhecimentos e as suas habilidades para uma tomada de atitude Que vai ao encontro das necessidades do outro. (GF5P8)

A tomada de consciência se dá através do conhecimento. (GF4PI)

Conforme demonstra o atributo consciência, tão enfatizado pelos participantes do grupo focal, para eles a palavra consciência significa conhecimento. Nesta perspectiva é importante explicitar o que a literatura diz sobre conhecimento.

O conhecimento é resultante de um saber organizado, elaborado. Está sempre em movimento e seus avanços levam às incertezas, Que conduzem a novos conhecimentos ${ }^{(10)}$. O processo de trabalho de cuidar também valoriza a técnica, pois está expressa a complexidade do cuidado e as competências do conhecer, do fazer e do ser enfermeiro $^{(11)}$

A consciência, como resultado do conhecimento preexistente e concretizado na ação como prática em movimento, Que possibilita criar, intervir, mudar e transformar concretiza-se na ação consciente, a partir do conhecimento organizado e sistematizado nas bases teóricas do saber da enfermagem.

A solidariedade é um sentimento próprio do ser humano, a se manifestar na relação com o outro. Nesta relação há respeito à individualidade dos seres envolvidos, os Quais interagem dando e recebendo afetividade, revelada no ato de cuidar e de receber cuidado solidário.

Conforme demonstraram os componentes do grupo focal, ao escolherem solidariedade como atributo essencial do cuidado, elas compreendem o ato de cuidar como sentido moral Que vincula o indivíduo à vida. Isto pode ser constatado nas seguintes falas:

A solidariedade no cuidado se mostra na forma de viver, de ser e de se expressar na relação com o outro. (GF4P5)

A solidariedade é inerente ao ser e viver do profissional de enfermagem. (GF4PI)

A solidariedade resultante da sensibilidade dos profissionais envolvidos no processo de cuidar contribui na identificação das necessidades singulares das pessoas, o Que por certo conduz à humanização no setor saúde Que transcende à competência técnocientifica - política dos profissionais Que participam desse processo.

Ao selecionarem os atributos do cuidado, a ética permeou a fala dos componentes do grupo focal em sessões distintas, a saber:

\section{Cuidar do outro é uma atitude ética. (GF3P9)}

\section{Não ser ético desqualifica o cuidado. Penso que sem ética não há cuidado. (GF4PI I)}

O cuidado é permeado de valores éticos, políticos, sociais e de cidadania Que vão ao encontro dos valores profissionais do cuidado. Isto o torna essencialmente humano. O cuidado envolve a moral e a ética e estes atributos contribuem para Que o cuidado de enfermagem atenda às necessidades do outro ${ }^{(12-13)}$.

A ética como atributo do cuidado faz deste uma ação valorativa, extensiva ao ser cuidado, ao cuidador e às situações a serem resolvidas no processo de cuidar. Neste atributo, a enfermeira toma consciência do cuidado como imperativo moral e ético que o faz evoluir no respeito à dignidade humana e à própria vida.

Entretanto, cuidado tem sentido de crescimento, pois no processo de cuidar existe uma relação Que se caracteriza por estar com a pessoa, no mundo dela. Assim, ambas crescem, o ser cuidado e o ser cuidador $^{(14)}$. Reafirmamos este autor, porQuanto o cuidado de Enfermagem vivenciado na relação dialógica construída no cuidado Que tem como atributos amor, zelo, consciência, solidariedade e ética, proporciona aos seres humanos envolvidos nesta relação crescimento individual e coletivo.

\section{Categoria 2}

\section{O cuidado de Enfermagem - antecedentes e consequentes}

Nesta categoria, verificamos as influências no cuidado de Enfermagem, o Qual tem relação com a etapa do Modelo de Análise de Conceito Evolucionário ${ }^{(2)}$, Que identifica os antecedentes ocorridos antes da existência do cuidado e os conseQüentes percebidos após a realização deste cuidado. Os eventos antecedentes e conseQuentes ao cuidado de Enfermagem foram colhidos por meio de respostas dadas pelos componentes do grupo focal às perguntas: "Quais os antecedentes do cuidado?" e "Quais os consequentes do cuidado?".

Foram citados como antecedentes do cuidado de enfermagem os seguintes: necessidades, conhecimento, sensibilidade, interação, escuta e interesse, e como conseQuentes: satisfação, bem-estar, cura, alívio, conforto, confiança, saúde e mudança no estilo de vida.

Para melhor compreensão do assunto apresentamos uma figurasíntese das discussões sobre os antecedentes e consequentes do cuidado de enfermagem enumerados pelos participantes do grupo focal a partir dos atributos escolhidos (Figura 1).

Compreender Que os antecedentes do conceito são situações, eventos ou fenômenos prévios ao conceito de interesse favoreceu o entendimento do contexto social no Qual o conceito é usado e também facilitou a compreensão do referido conceito. Assim, os participantes do grupo focal apontaram como antecedentes do cuidado:

A identificação das necessidades do paciente antecede o cuidado por ser esta indispensável à construção do cuidado Que se dá na 


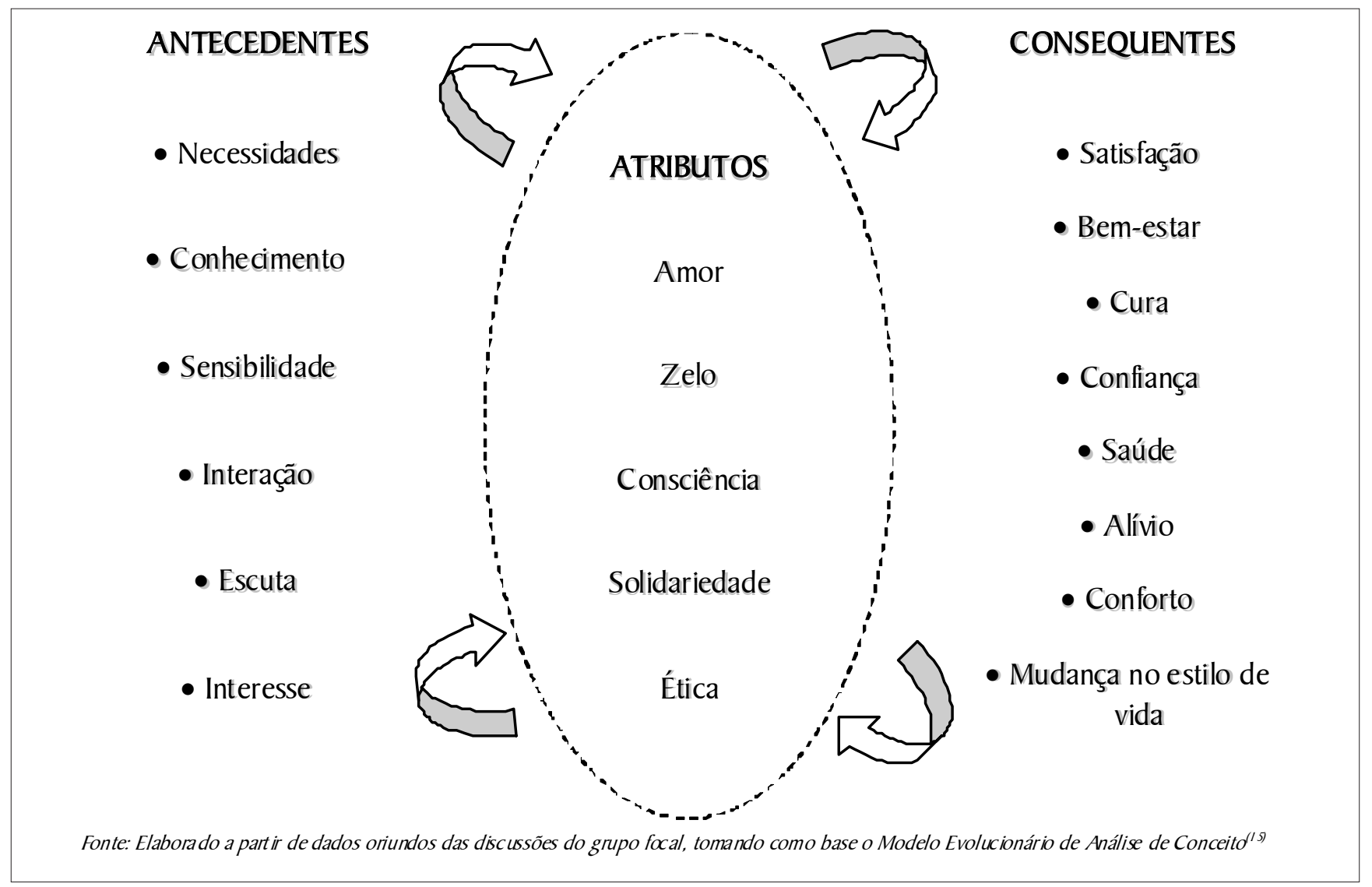

Figura I. Antecedentes e consequentes do cuidado de enfermagem.

relação enfermeiro-paciente. (GF5PI)

O conhecimento é fundamental e antecede a identificação das necessidades do paciente, o conhecimento nos dá segurança. (GF5P4)

A sensibilidade aliada ao conhecimento nos faz perceber o outro, identificar suas necessidades e planejar o cuidado. É Quando se alia conhecimento, intuição, percepção e solidariedade. (GF5P6)

A interação como espaço de encontro com o outro é de grande importância no cuidado de Enfermagem. (GF5P7)

Sem escuta não há cuidado. É por meio dela que conhecemos as necessidades do outro. Ela facilita a interação enfermeiro-paciente. (GF5P3)

O interesse pelo outro leva ao conhecimento de suas necessidades, faz fluir a sensibilidade e interação para um cuidado Que envolve e transforma paciente-enfermeira. (GF5PI3)

Percebemos, pelas falas, como os participantes foram crescendo nas sessões do grupo focal, estabelecendo conexões importantes para a compreensão do Que antecede o cuidado de enfermagem e oferecendo meios para a construção do conceito de cuidado de enfermagem, objetivo deste estudo. Em estudo semelhante foi evidenciada a intuição como forma de conhecimento e sentimento Que influenciam o cuidado de enfermagem ${ }^{(16)}$.
De acordo com os participantes, a identificação das necessidades do paciente foi apontada como antecedente do cuidado e Que ocorre durante a realização do histórico de enfermagem, Quando a enfermeira toma conhecimento da história de vida do paciente e, com base nesta, tem condições de identificar suas necessidades e tentar atendê-las.

O conhecimento foi apontado pelo grupo focal como fundamental e antecedente ao processo de cuidar. E este é ressaltado como condição indispensável à identificação das necessidades do paciente Que, obrigatoriamente, antecede Qual Quer plano de ação, prescrição ou intervenção da Enfermagem.

O conhecimento enriquece o cuidado de enfermagem, sendo fundamental para Que possamos compreender melhor as necessidades dos clientes em situações decisivas entre vida e morte, saúde e doença $a^{(17) .}$

O conhecimento no processo de cuidar em enfermagem é ampliado na relação estabelecida entre cliente e enfermeiro, porQuanto o cuidado é constantemente reconstruído em seu processo dinâmico, inovador e transformador. A sensibilidade antecede o cuidado porQue é dela Que flui a identificação das necessidades do outro, a Qual, por sua vez, é possível pelo conhecimento apreendido anteriormente. A literatura reforça Que a enfermagem deve desenvolver abertura e flexibilidade para trabalhar como paciente associado a conhecimento, sensibilidade e comportamento ${ }^{(18)}$.

A interação, como resultado do encontro entre seres humanos, é de importância vital para atender as necessidades do cliente relacionadas não apenas ao biológico, mas também aos aspectos psicológicos, sociais e espirituais. Destarte, na construção do cuidado, 
a interação, além de aliar os aspectos mencionados, possibilita a inter-relação entre o conhecimento, a sensibilidade e a solidariedade.

A interação e o interesse foram aspectos constantes nas falas dos participantes do grupo focal. Portanto, perceberam Que o interesse facilita a interação entre paciente-enfermeira, pois ao demonstrar atenção a enfermeira já motiva certa interação a se ampliar no processo relacional estabelecido entre eles. Resultado da integração que flui da inter-relação entre ser cuidado e ser cuidador no processo de trabalho da enfermagem, a interação propicia um cuidado comprometido com a Qualidade de vida dos seres humanos envolvidos nessa relação. Ela é, sem dúvida, um aspecto marcante no processo de cuidar em Enfermagem, pois contribui para serem identificadas as necessidades do paciente de forma participativa e integrativa, trazendo satisfação para ambos.

Segundo a fala das participantes, a escuta foi mencionada como um antecedente essencial ao conhecimento do paciente como possibilidade de identificar suas necessidades mostrar-lhe atenção e demonstrar empatia. Esta deve ser atenta com vistas a uma compreensão lógica e ao mesmo tempo sensível às necessidades de cuidado do paciente.

Na relação de cuidar estão atenção, paciência, discernimento e percepção aguçada. Para tanto, a enfermeira deve disponibilizar um tempo hábil a fim de colher desta escuta informações Que possam subsidiar a identificação das necessidades do paciente e, desse modo, planejar e desenvolver cuidados destinados a atender a estas necessidades.

Sob esse prisma, podemos afirmar Que, ao ouvir o paciente, é preciso estar atento para não julgar o conteúdo do pensamento expresso e concentrar toda a atenção nele, pensar reflexivamente sobre o Que ele diz; tentar compreender o Que está sendo dito e também o Que não está por meio da observação da comunicação não verbal e paraverbal $^{(19: 79)}$

Após discutirmos os antecedentes do cuidado de enfermagem nos deteremos nos conseQuentes. Consequentes do cuidado são os acontecimentos decorrentes do cuidado de enfermagem manifestados na prática. Os eventos consequentes (resultantes) são importantes porque geram novas propostas às pesquisas, o que viabiliza um estudo mais abrangente de todas as características e formas de conceito ${ }^{(20)}$.

Para os participantes do grupo focal, são consequentes do cuidado: a satisfação; o bem-estar; a cura; a confiança; a saúde; o alívio; o conforto; e a mudança no estilo de vida.

Percebo Que cuidei Quando vejo a satisfação do paciente, por meio do seu olhar Que comunica um sentimento de prazer. (GF5P3)

O bem-estar proporcionado pelo cuidado é indescritível, no entanto, é percebido na relação de cuidado, tanto pelo enfermeiro Quanto pelo paciente, pela sensação de zelo que este traz. (GF5P5)

Quando o paciente obtém cura e recebe alta, sinto Que meu trabalho teve resultado. A volta do paciente à sociedade é a minha maior recompensa. (GF5P7)

A confiança Que se estabelece na relação paciente-enfermeira é uma conseqüência e ao mesmo tempo resultado de Que houve cuidado. (GF5P8)

A recuperação da saúde é uma conseqüência do cuidado de

\section{Enfermagem. (GF5PI3)}

O alívio da dor é uma conseqüência do cuidado e este resultado é perceptível para todos. Sai da subjetividade para o real. (GF5PI I).

Quando há relação há interação, conforto e satisfação para o paciente-enfermeira. O conforto é uma conseqüência objetiva do processo de cuidar em Enfermagem. (GF5PI0)

A mudança no estilo de vida do paciente é uma conseqüência do cuidado Que depende da interação, das informações/orientações dadas pela enfermeira e da confiança estabelecida entre o ser cuidado e o ser Que cuida. (GF5PI2)

Como evidenciamos pelas falas, a satisfação proporcionada pelo cuidado é vista pelos participantes do grupo focal como algo perceptível, demonstrado no olhar e na expressão de sentimento de prazer ocorridos na comunicação não-verbal existente na relação/ interação estabelecida entre paciente-enfermeira. Esta se confunde com o bem-estar, o Qual, mesmo tendo sido relatado como indescritível, é percebido Quando existe uma interação entre seres humanos Que se comunicam no processo de relação de cuidar.

A cura como possibilidade de resgate da saúde, embora o ser humano viva sempre num processo saúde-doença, constitui-se uma busca incessante tanto do paciente Quanto da profissional enfermeira. A ausência de cuidado impossibilita a cura de Qualquer transtorno físico e psicológico, pois, ao adoecer, o ser humano traz envolto neste processo de adoecimento todo o seu ser bio-psico-sócioespiritual.

Outro consequente do cuidado é a confiança. O dicionário afirma Que a confiança diz respeito à segurança, crédito, fé e credibilidade ${ }^{(8)}$. Apesar de ter sido colocada como consequente do cuidado, nas discussões do grupo focal, em alguns momentos das falas dos participantes do referido grupo, esta antecede, muitas vezes, o cuidado e facilita a comunicação entre enfermeira e paciente.

De acordo com os participantes do grupo focal, a saúde também foi apontada como consequente do cuidado de enfermagem e para eles esta constitui-se um resultado positivo tanto para os profissionais envolvidos no processo de cuidar como para os seres humanos cuidados.

Ademais, o restabelecimento da saúde do paciente concretizado na cura revela-se no alívio e conforto expressados por este, assim como pela enfermeira, a Qual, ao prestar cuidado e perceber os resultados, também se mostra aliviada e confortada pela demonstração de bem-estar, alívio, conforto, satisfação e saúde do paciente.

Outro consequente do cuidado é a mudança no estilo de vida, caracterizada como um processo lento e dinâmico e só possível se houver paciência, confiança, inter-relação e comunicação. Ela exige da enfermeira e do cliente persistência, determinação e coragem para enfrentarem os deslizes ocorridos neste processo de mudança.

\section{Categoria 3}

\section{O significado do cuidado - o concreto e o subjetivo na relação entre seres humanos}

Conforme as falas dos participantes do grupo focal evidenciaram, para eles o significado do cuidado de enfermagem é: 
Ter atitude para com o outro. Demonstrar interesse. Oferecer proteção, zelo, atenção, amor e solidariedade. (GF6P3)

Utilizar seu saber e seu fazer em benefício do outro. Dar-lhe conforto, segurança, atenção, respeito e amor. (GF6P5)

Verificar Que sua ação contribuiu para recuperação da saúde do outro. (GF6PI I)

Quando o paciente toma consciência Que minha ação o ajudou. Quando ele a julga importante. (GF6P I0)

Estas falas mostram claramente Que os significados do cuidado se apresentam na expressão do sentido atribuído pelo ser cuidado à ação de cuidar. Para os participantes do grupo, o significado do cuidado de Enfermagem está atrelado à percepção objetiva do resultado da sua ação, e envolve relação, interação, saber-fazer, contribuição e transcendência na relação.

Nas falas dos participantes os procedimentos e técnicas de enfermagem não foram explicitados. Assim, os participantes foram coerentes com os atributos gerais e essenciais ao conceito de cuidado de enfermagem. Para eles, o Que dá significado a este cuidado é a existência de um ser carente de necessidades e de outro ser capaz de suprir essas necessidades. Como deixam claro, o cuidado é individualizado, tem conhecimento próprio da enfermagem, requer empatia, interação, transcendência e tem valor para Quem o recebe.

É válido enfatizar Que durante a realização das sessões houve crescimento individual e coletivo no grupo, pelo entendimento dos conceitos explicitados e trabalhados nas sessões grupais e, ainda, pelo relato das vivências das enfermeiras e alunos participantes do grupo. Em estudo reflexivo sobre o cuidar e o educar em enfermagem foram evidenciados saberes nas escalas criativa, estética, ética, política e técnica e que a capacidade para intervir está relacionada à integração dos saberes ${ }^{(21)}$.

O concreto do significado do cuidado de enfermagem parece estar nos resultados observados pelos profissionais, no seu processo de cuidar, Quando estes percebem ter havido atendimento das necessi-dades do outro e até mesmo das suas necessidades. A literatura aponta que o conceito de cuidado é complexo e não tem conceito único ${ }^{(22)}$.

De modo geral, o significado do cuidado está atrelado à percepção do Que está subjacente no processo relacional enfermeiro-paciente e este necessariamente não é perceptível para Quem está fora desta relação. Assim, perceber o significado do cuidar é algo concretizado por meio da sensibilidade, afetividade e interação presentes no cuidado de enfermagem.

\section{O conceito de cuidado de enfermagem construído}

No processo de construção do conceito de cuidado de enfermagem, consoante os participantes do grupo focal compreenderam, as sessões foram momentos de discussão e aprendizagem significativas. As informações resgatadas e construídas por meio das vivências relatadas por alguns participantes mais experientes no processo de cuidar conjugaram-se à experiência dos demais participantes e o resultado desta vivência de aprendizagem culminou com o conceito - construído coletivamente - num processo de criação/sedimentação ocorrido na relação dialógica resultante do encontro entre teoria e prática, conhecer-fazer concretizado no seguinte conceito então elaborado:

Cuidado de enfermagem é um fenômeno intencional, essencial à vida, Que ocorre no encontro de seres humanos Que interagem, por meio de atitudes Que envolvem consciência, zelo, solidariedade e amor. Expressa um "saber-fazer" embasado na ciência, na arte, na ética e na estética, direcionado às necessidades do indivíduo, da família e da comunidade.

O conceito de cuidado de enfermagem construído é fruto de uma organização mental, explicitada com base em outros conceitos, discutidos amplamente. No entanto, este foi elaborado a partir do intenso debate nas várias sessões grupais, cujos atributos, significados, antecedentes e consequentes iam surgindo nas falas dos participantes.

Salientamos que a vivência do aprender-ensinar-fazer dos participantes deste estudo, bem como o debate ensejado nas sessões do grupo focal permitiram a elaboração do referido conceito Que fluiu de forma criativa, construtiva e prazerosa na relação de pessoas Que cuidam do ensinar, do aprender, do fazer e do ser e conviver na enfermagem.

\section{CONSIDERAÇÕES FINAIS}

Iniciamos esta reflexão explicitando a in\&uietação sobre o conceito de cuidado de enfermagem. Conforme percebíamos, este também circundava o caminhar profissional de muitas enfermeiras. O foco da nossa atenção como profissionais da assistência e do ensino sempre esteve voltado para o processo de cuidar em Enfermagem, para a compreensão e execução deste e para as condições nas Quais este cuidado é prestado.

De modo geral, no desenvolvimento do estudo ora apresentado, as dificuldades foram frutos da nossa ansiedade. A cada Quinze dias, antes do horário marcado, sentíamos muita insegurança acerca do comparecimento dos participantes do grupo. Para nossa alegria, a participação foi muito boa e as poucas faltas ocorridas foram justificadas por motivos pertinentes. Nas nove sessões do grupo focal, os encontros constituíram-se momentos de prazer e congraçamento.

A realização de estudo para elaboração de um conceito de cuidado de Enfermagem, envolvendo atores diferenciados, teve a perspectiva do novo, embasado em análise de conceito, efetuada na primeira fase do estudo. Ademais, na discussão coletiva, impulsionou a construção de um conceito de cuidado de Enfermagem sem pôr em cheque as condições dos participantes do grupo para esta formulação. Isto foi possível graças à confiança depositada nas pessoas e na crença de Que a discussão coletiva bem fundamentada, permeada de relatos de casos reais, de experiências vividas e da possibilidade de ampliar o conhecimento, por meio do debate franco, sem subterfúgios ou medo de contestações, mas, com a certeza de Que todo conhecimento pode e deve ser discutido, refutado, ampliado, construído, desconstruído e reconstruído a partir da ação Que é dinâmica e plena de novas possibilidades.

Encerramos esta pesQuisa com a compreensão de Que construir um conceito de cuidado de Enfermagem à luz do Modelo Evolucionário de Análise de Conceito de Rodgers deu-nos subsídios para um trabalho coletivo mediado pelas sessões do grupo focal, com a compreensão de Que a elaboração do conceito de cuidado ultrapassou a apreensão do significado, do conhecimento dos atributos, antecedentes e conseQuentes deste cuidado.

Esta construção propiciou-nos o prazer de caminhar com os outros, ouvindo, mediando, sentindo, percebendo, interpretando e comungando idéias numa relação afetiva, efetiva, criadora, inovadora. 
Desse modo, da relação vivenciada brotou um conhecimento Que proporcionou a cada participante um crescimento individual e coletivo.

Esperamos Que o conceito produzido contribua para novos estudos e debates em espaços de educação e saúde, ensino e serviço, ou onde houver seres humanos carentes do cuidado de enfermagem, tão importante à promoção da vida, vida digna, justa, solidária e cidadã.

\section{REFERÊNCIAS}

1. Heidegger M. Ser e tempo. 1 I a ed. Petrópolis: Vozes; 2001.

2. Rodgers BL. Concepts, analysis and development of nursing knowledge: the evolutionary cycle. I Adv Nurs 2006; I 4(4): 330-5.

3. De Domenico EBL, Ide CAC. Referências para o ensino de competências na enfermagem. Rev Bras Enferm 2005; 58(4): 453-7.

4. Turato ER. Tratado da metodologia da peseuisa clínicoQualitativa: construção teórico-epistemológica, discussão comparada e aplicação nas áreas da saúde e humanas. Petrópolis: Vozes; 2003

5. Minayo MCS. O desafio do conhecimento: pesquisa Qualitativa em saúde. 9ª ed. São Paulo: Hucitec; 2006

6. Kavern I, Webb C. Focus groups as a tool for critical social research in nurse education. Nurs Educ 200 I; 2 I (4): 323-33.

7. Ministério da Saúde (BR). Conselho Nacional de Saúde, Comissão Nacional de Ética em Pesquisa. Resolução № 196 de 10 de outubro de 1996: aprova as diretrizes e normas regulamentadoras de pesQuisa envolvendo seres humanos. Brasília: Ministério da Saúde; 1996.

8. Ferreira ABH. Novo dicionário básico de língua portuguesa. Rio de Janeiro: Porto; 2009

9. Bison RAP, Furegato ARF, Santos JLF. La percepción del cuidar entre estudiantes y profesionales de enfermería. Index Enferm 2007; I6(56).

10. Morin E. Os sete saberes necessários à educação do futuro. $3^{\mathrm{a}}$ ed. São Paulo: Cortez; 2003.

I I. Tanaka LH, Leite MMJ. O cuidar no processo de trabalho do enfermeiro: visão dos professores. Rev Bras Enferm 2007; 60(6): $681-6$.
12. Casate IC, Correa AK. Humanização do atendimento em saúde: conhecimento veiculado na literatura brasileira de enfermagem. Rev Latino-am Enfermagem 2005; 13(1): 105-I I.

13. Stamm M. Evolução do cuidado na enfermagem até o cuidado transdimensional: uma revisão de literatura. Ciênc Cuidado Saúde 2002; I (2): 293-8.

14. Mayeroff M. On caring. New York: Harper Perennial; 1990.

15. Rodgers BL, Knafl KA. Concept development in nursing: foundations techniques and applications. Philadelfia: WB Saunders; 2000

16. Silva AL, Baldin SM, Nascimento KC. O conhecimento intuitivo no cuidado de enfermagem. Rev Bras Enferm 2003; 56(1): 7-11.

17. Oliveira MC. Os modelos de cuidados como eixo de estruturação de atividades interdisciplinares e multiprofissionais em saúde. Rev Bras Educ Med 2008; 32(3): 347-55.

18. Eunyoung $\mathrm{E}$. The model of cultural competence through an evolutionary concept analysis. I Trasn Nurs 2004; 15(2): 93 102.

19. Stefanelli MC. Comunicação não-terapêutica e barreiras à comunicação terapêutica. In: Stefanelli MC, Carvalho EC, organizadores. A comunicação nos diferentes contextos da enfermagem. Barueri: Manole; 2005.

20. Walker I, Avant KC. Strategies for theory construction in nursing. $4^{\mathrm{a}}$ ed. London: Prentice Hall; 2004.

21. Ferraz F, Silva LWS, Silva LAA, Reibnitz KS, Backes VMS. Cuidareducando em enfermagem: passaporte para o aprender/educar/ cuidar em saúde. Rev Bras Enferm 2005; 58(5): 607-10.

22. McCane T. A concept analysis of caring. In: Cutcliffe JR, McKenna HP, editores. The essential concepts of nursing. New York: Elsevier/Churchill Livingstone; 2005. p. 33-50. 